\title{
The Load Capacity Model and Experimental Tests of a New Yielding Steel Prop
}

\author{
Yanlong Chen, ${ }^{1,2}$ Yang Hao, ${ }^{1}$ Yu Wu, ${ }^{1,2}$ Kai Zhang, ${ }^{1,2}$ and Guimin Zhang ${ }^{2}$ \\ ${ }^{1}$ State Key Laboratory for Geomechanics and Deep Underground Engineering, China University of Mining \& Technology, \\ Xuzhou 221116, China \\ ${ }^{2}$ School of Mechanics and Civil Engineering, China University of Mining \& Technology, Xuzhou 221116, China
}

Correspondence should be addressed to YuWu; wuyu@cumt.edu.cn

Received 29 August 2017; Accepted 14 November 2017; Published 27 December 2017

Academic Editor: Roman Wendner

Copyright (c) 2017 Yanlong Chen et al. This is an open access article distributed under the Creative Commons Attribution License, which permits unrestricted use, distribution, and reproduction in any medium, provided the original work is properly cited.

\begin{abstract}
As the mining depth increases year by year, the deformation and failure of deep roadway become more and more serious, and new support equipment with high supporting force and yieldable character is quite necessary for mining safety. In this research, a new yielding steel prop with high stable load capacity was introduced, which features sustaining large deformation in the field. Based on principle stress method and elastic-plastic theory, a mathematical model of load capacity was proposed for the new prop. The results show that the stable load capacity of the prop increases linearly with the increase of the effective number of the steel balls. Meanwhile, the stable load capacity of the prop increases initially and decreases afterwards with the increase of the radius of the steel ball. Under the fixed radius of the steel ball, the stable load capacity will increase with the decrease of the gap between the inner tube and the outer tube. The stable load capacity of the prop calculated using the theoretical model quantitatively agrees with that of the experimental tests, with only an error within $5 \%$.
\end{abstract}

\section{Introduction}

Due to the large-scale exploitation in recent years, shallow coal resources gradually decrease and the mining depth increases year by year in China. Currently, most of the Chinese eastern mining areas have entered into a state of deep mining [1-4]. Affected by the complicated mechanical environment, the geologic mechanical environment of the deep strata is greatly different from the shallow one, which makes the surrounding rock in deep roadways possess some unique properties, such as complexity of stress field, great deformation, and high rheological property [5-7]. In addition, with the increase in mining depth, ground stress and deformation of surrounding rock in roadways become larger and make it challenging for the support of deep roadway [8-10].

With regard to deep roadway support, a great number of scientific researches and experimental work have been done in China [11-16]. At present, bolt support has caused widespread concern and is widely used in deep mines [1722]. However, under the conditions of deep mining, as rocks are broken or loosen with bad bolt ability, the bolt support is difficult to satisfy the requirement of support for deep rock roadway with high stress and large deformation. On the other hand, some special support technologies, such as the large diameter and high stress overlong bolt and bolt-grouting combined support, also cannot be used extensively under such conditions, due to the need of special equipment and technology. Similarly, because of the high support cost, low construction speed, and maintenance difficulty after failure, passive support patterns such as arching and metallic lining cannot satisfy the requirements of support for deep roadway $[3,8,23-25]$.

As it is known, hydraulic prop is another common support method in roadways of coal mines [26-28], whose designed load capacity usually ranges from 200 to $300 \mathrm{kN}$ in China. Due to the high stress conditions in deep mining, unloading of the hydraulic prop often occurs when the roof pressure is beyond its load capacity, which causes serious mining disasters. Besides, the hydraulic prop is a nonyielding design prop, and it cannot fit the large deformation of roof in deep coal mines. Furthermore, the emulsion in prop is 


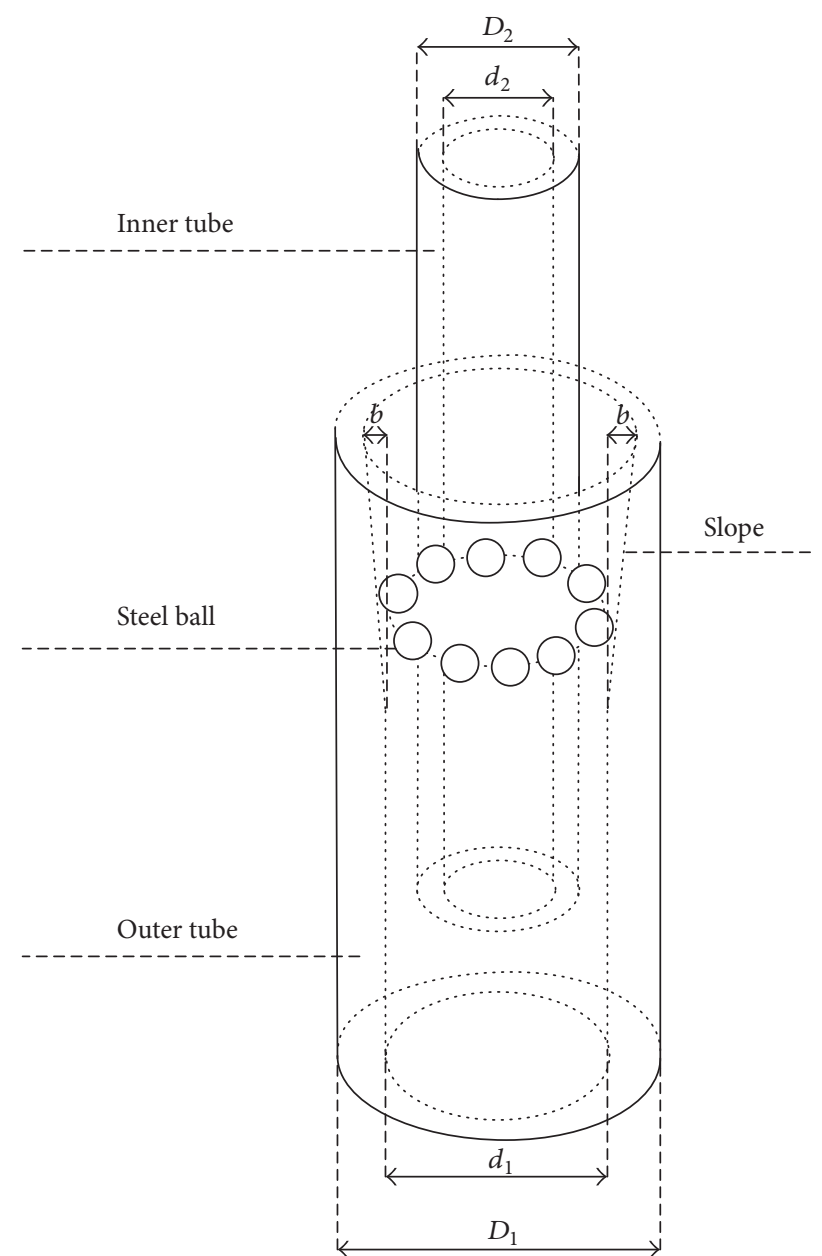

FIGURE 1: The schematic diagram of the new yielding steel prop.

discharged directly on the spot, which may pollute the underground water in mining area seriously.

Because of the high stress and large deformation of the surrounding rock masses in deep roadway, new support structures are quite necessary for mining safety. The support structures must not only own high and stable load capacity but also sustain considerable large deformation before yield. Some researcher has proposed some yielding props [29]; however, theoretical assessment of load capacity of the prop is still not clarified until now, which limits the design and application of the yielding props. In the present study, the structure of a new yielding steel prop was first illustrated. Then, based on the principle stress methodology and elasticplastic theory, mechanical and mathematical models were proposed for the new prop, and the stable load capacity of the prop was evaluated. Finally, experimental tests were conducted to study the response of the new prop and verify the theoretical model.

\section{The Illustration of the New Yielding Steel Prop}

The new yielding steel prop was designed, as indicated in Figure 1, which consists of an outer tube, an inner tube, and lots of steel balls. The inner diameter and the outer diameter of the outer tube are $d_{1}$ and $D_{1}$, respectively. The inner diameter and the outer diameter of the inner tube are $d_{2}$ and $D_{2}$, respectively. In addition, the inner face of the outer tube is partially with a slope whose height is $b$. The steel ball is located between the outer wall of the inner tube and the inner wall of the outer tube. The diameter of the steel ball is selected by

$$
\frac{d_{1}-D_{2}}{4}<R<\left(\frac{d_{1}-D_{2}}{4}+b\right)
$$

where $R$ is the radius of the steel ball.

The working mechanism of the new yielding steel prop is that the steel balls gouge the inner and outer tubes, and the prop provides the load capacity by generating plastic yield in the contact area. When the inner tube suffers an increasing load, the axial support load of the prop also increases until the stable load capacity is reached. Initially, the type of contact of steel ball with the inner and outer tubes belongs to pointto-point contact, which generates stress concentration. When the contact stress is higher, the inner and outer tubes undergo plastic yield in the contact area with the steel balls digging into them. It is assumed that each steel ball and inner tube maintain a relatively stable state of motion, and the gouging process of each steel ball is the same, including elastoplastic stress, strain, displacement, and plastic distribution. Because each steel ball makes the same contribution to the load capacity of the prop, the prop can be considered as an axisymmetric structure. Therefore, the working mechanism of one steel ball gouging inner and outer tubes should be made clear, and then the stable load capacity of the whole prop can be estimated.

When the new yielding steel prop suffers from an increasing load, the strained condition of the outer and inner tubes can be divided into four stages, as displayed in Figure 2. In the initial stage, when the prop does not suffer the load, the prop is under the equilibrium state (see Figure 2(a)). When the inner tube is loaded, the contact areas between the steel balls with the outer and inner tubes are elastic (see Figure 2(b)). With the load increasing, plastic deformation begins to take place around the contact areas (see Figure 2(c)). With the continued increase of the embedded depth of the steel ball, the load capacity of the prop is also increased. Then, the prop reaches the stable load capacity and the inner tube moves downwards continuously (see Figure 2(d)).

\section{The Load Capacity Model of the New Yielding Steel Prop}

3.1. The Mechanical Model of One Steel Ball Contacting with the Inner and Outer Tubes. To propose a mechanical model of the load capacity for the prop, assumptions that have been adopted are given below.

(1) The material of the prop shows perfectly plastic behavior.

(2) The deformation of the steel balls is neglected.

(3) The materials of the inner and outer tubes are the same. 


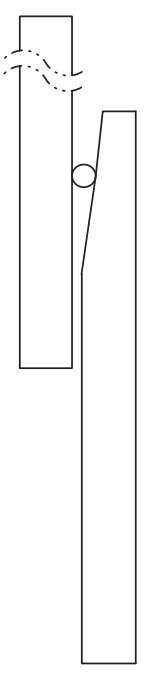

(a)

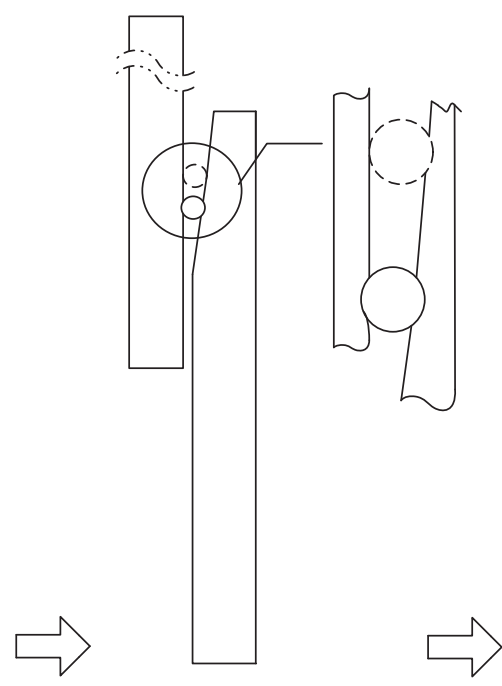

(b)

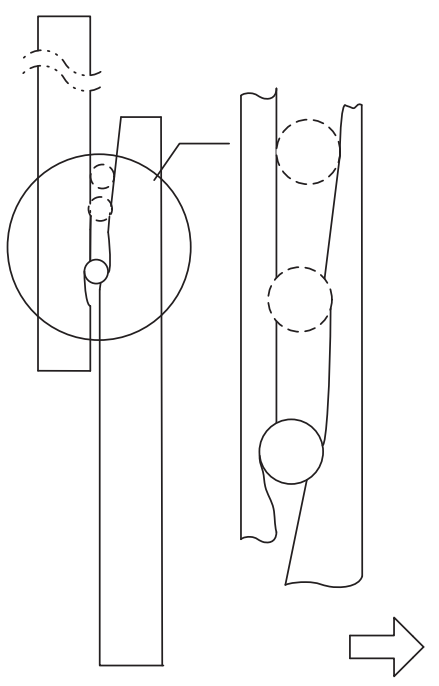

(c)

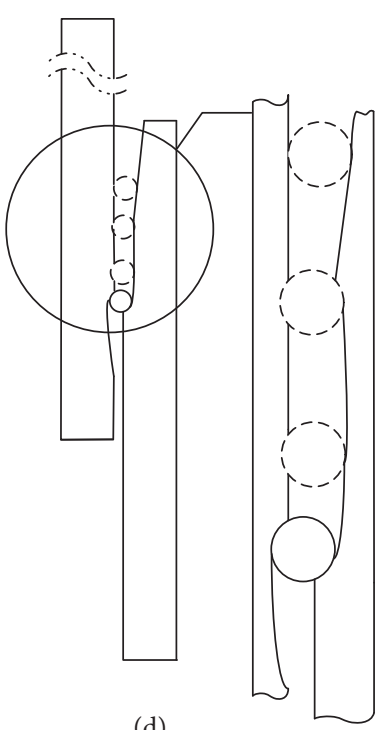

(d)

FIGURE 2: Four stages when the new yielding steel prop suffers from an increasing uniform load. (a) Equilibrium stage of the prop without load; (b) elastic stage of the contact area; (c) plastic deformation starts to form around the contact area; (d) prop deforms with stable load capacity.

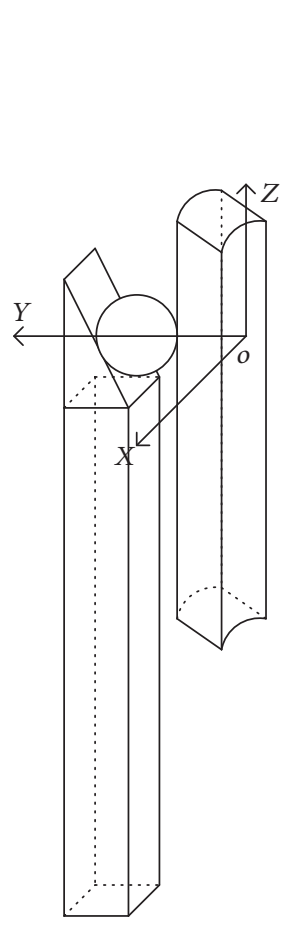

(a)

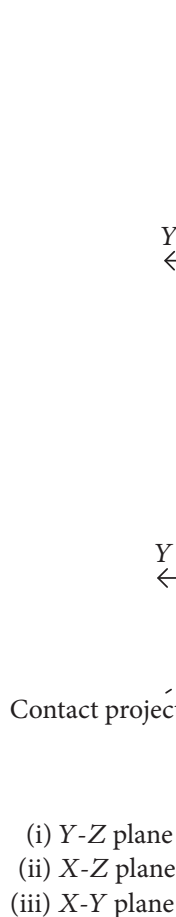

(iii) $X-Y$ plane

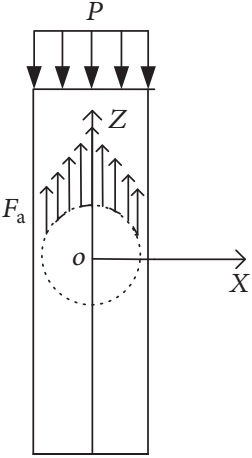

(ii)

FIgURE 3: The simplified plane mechanical model of the new yielding steel prop. (a) The initial stage of the prop without load; (b) three-view drawing of the prop under stable load capacity.

(4) Under the stable load capacity, the steel ball does not rotate or have rotation trend.

(5) The embedded depths of the steel ball in inner and outer tubes are approximately equal.

The simplified plane mechanical model of the new yielding steel prop was built as Figure 3. In Figure 3, $P$ is load capacity of the prop with one steel ball, $R$ is the radius of the steel ball, $F_{\mathrm{a}}$ is axial force, $F_{\mathrm{r}}$ is radial force, and $L$ is the gap distance between the inner and outer tubes.

Under the stable load capacity state, the steel ball has both constant axial and radius forces. The axial force can support the capacity load, and the radius force causes plastic zone on the contact surface of the inner and outer tubes. 

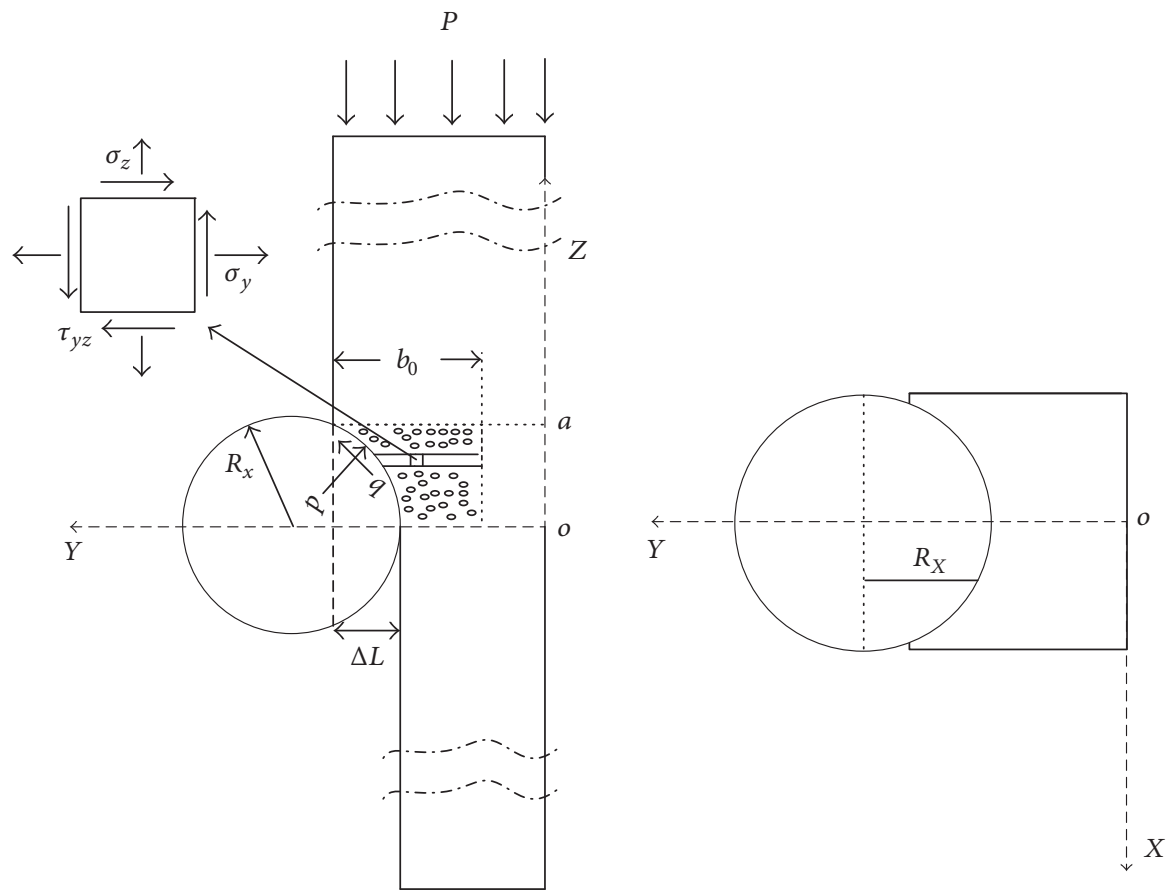

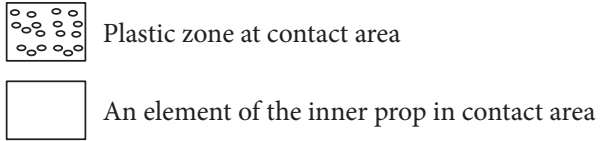

FIGURE 4: The specific cross-section of contact area between the steel ball and the inner tube. $\Delta L$ is embedded depth between the steel ball and inner tube in $X$ position in a specific cross-section of contact area, $a o$ is the projection of the contact area in $Z$ direction, $R_{X}$ is the radius of cross-section of the steel ball in $X$ position, $b_{0}$ is the maximum plastic zone depth in $Y$ direction under the stable load capacity, and $p$ and $q$ are the normal force and twisting force, respectively.

The mechanical essence of the steel ball contacting with inner and outer tubes is a space axisymmetric elastoplastic contact problem, and the ideal solution is space-solving method. However, due to the complexity of the contact problem, it is difficult for the space problem to obtain an analytical solution using the mathematic solving method. In order to simplify the problem, the elastoplasticity principal stress method is applied here, which can convert space problem to plane problem in the contact area. A specific cross-section parallel with $Y-Z$ plane of the contact area between the steel ball and the inner tube is presented in Figure 4 . The stress in a representative element is analyzed. Then, integrating the axial in contact area projection in $X-Y$ plane, the stable load capacity of the prop with one steel ball can be obtained as

$$
P=\iint_{A} F_{\mathrm{a}} \mathrm{d} A,
$$

where $P$ is load capacity of the prop with one steel ball, $F_{\mathrm{a}}$ is axial load of each contact node, and $A$ is the contact projection area.

As the gap between the outer and inner tubes is constant, the relationship between $R_{X}$ and the embedded depth $\Delta L$ is

$$
R_{X}-\Delta L=\frac{L}{2}
$$

$$
L=\frac{d_{1}-D_{2}}{2},
$$

where $R_{X}=\sqrt{R^{2}-x^{2}}$, ranging from $L / 2$ to $R$, and $L$ is the gap between the inner and outer tubes.

The maximum embedded depth $\left(\Delta L_{\max }\right)$ is defined as

$$
\Delta L_{\text {max }}=R-\frac{L}{2} .
$$

\subsection{The Mathematical Model of One Steel Ball Contacting with the Inner and Outer Tubes}

3.2.1. The Equilibrium Differential Equation. Based on the contact mechanics [30], the analysis of the axial force can follow the example of the expertise theory of the roll $[31,32]$. As the sum of forces in the $Z$ direction is equal to zero, the equilibrium differential equation of the prop can be defined as

$$
\begin{aligned}
& b(z) \frac{d \bar{\sigma}(z)}{d z}+\bar{\sigma}(z) \frac{d b(z)}{d z}+\frac{z}{\sqrt{R_{X}^{2}-z^{2}}} p(z)+q(z) \\
& \quad=0
\end{aligned}
$$

where $z$ is the contact location between the steel ball and the inner tube, $b(z)$ is the plastic zone depth of the prop in the 
$Y$ direction, $\bar{\sigma}(z)$ is the average longitudinal stress in the $Z$ direction, and $p(z)$ and $q(z)$ are the compressive stress and shear stress along the contact arc length, respectively.

3.2.2. Plastic Yielding Criteria. It is assumed that the stresses in the $Y$ direction of all elements are approximately equal:

$$
\sigma_{y}(y)=-p \sin \theta
$$

where $\cos \theta=z / R_{X}$ and $\sin \theta=\sqrt{R_{X}^{2}-z^{2}} / R_{X}$.

The shear stress decreases linearly along the $Y$ direction:

$$
\tau_{y z}(y)=\frac{(q+p \sin \theta) y}{b_{0}} .
$$

The plastic yielding criteria of the element are obtained by Tresca criteria:

$$
\left(\sigma_{z}-\sigma_{y}\right)^{2}+4 \tau_{y z}^{2}=Y_{S}^{2}
$$

From (7), (8), and (9),

$$
\sigma_{z}+p=\frac{Y_{S}}{\sqrt{1-\left(2(q+p \sin \theta) y / b Y_{S}\right)^{2}}} .
$$

Assuming the stresses in the $Z$ direction are approximately equal; that is,

$$
\sigma_{z}(z)=\bar{\sigma}_{z}(z)
$$

Substituting (11) into (10),

$$
\bar{\sigma}_{z}(z)+p=Y_{S} I(m)
$$

where $I(m)=\left(\sin ^{-1} m+m \sqrt{1-m^{2}}\right) / 2 m, m=2(q+\sin \theta) / Y_{S}$

Because $\sqrt{1-m^{2}} \geq 0$, the value of $m$ is from 0 to 1 ; then the $I(m)$ ranges from $\pi / 4$ to 1 . Therefore, (12) is approximately rearranged as

$$
\bar{\sigma}_{z}(z)+p \sin \theta \approx Y_{S}
$$

3.2.3. The Plastic Zone Depth in the Y Direction. As the deformation of the steel ball is negligible and the shape of the ball remains constant, in the contact area, the plastic zone depth of the inner tube in the $Y$ direction can be defined as

$$
b(z)=b_{0}+\frac{L}{2}-\sqrt{R^{2}-x^{2}},
$$

where $b_{0}$ is the maximum plastic zone depth in the $Y$ direction under the stable load capacity, which will be determined in the following section by numerical simulation.

3.2.4. The Equation of the Stable Capacity Load. Substituting (13) into (6), (6) can be arranged as

$$
\begin{aligned}
\frac{d p(z)}{d z}= & \frac{Y_{S}-p(z) \sin \theta}{b(z)} \frac{d b(z)}{d z} \\
& +\left(\mu+\frac{z}{\sqrt{R_{x}^{2}-z^{2}}}\right) \frac{p(z)}{b(z)} .
\end{aligned}
$$

In the region of contact area between the steel ball and the inner tube, the frictional traction is related to the pressure by the coulomb law:

$$
q(z)=\mu p(z)
$$

where $\mu$ is the frictional coefficient of the contact surface.

Based on the geometric relationship among $x, y$, and $z$,

$$
z=\sqrt{R^{2}-x^{2}-y^{2}}
$$

Then, according to (14), (16), and (17), the partial differential equation of $p(z)$ can be replaced by $p(x, y)$. So the component of each node for the axial force can be calculated as

$$
d p=F_{a}=p(x, y) \times(\cos \theta+\mu \sin \theta) d x d y .
$$

Consequently, integrating (17), the axial force of one steel ball gouging the inner tube can be written as

$$
P=\iint_{A} p(x, y) \times(\cos \theta+\mu \sin \theta) d y d x .
$$

3.2.5. Boundary Conditions. The displacement boundary conditions are

$$
\begin{aligned}
& b(o)=b_{0}-\Delta L \\
& b(a)=b_{0} .
\end{aligned}
$$

The stress boundary conditions are

$$
\begin{aligned}
& p(o)=0 \\
& p(a)=0 .
\end{aligned}
$$

And, the range of contact area in $X-Y$ plane is

$$
\begin{aligned}
& x \in\left[-\sqrt{R^{2}-\frac{L^{2}}{4}}, \sqrt{R^{2}-\frac{L^{2}}{4}}\right] \\
& y \in\left[\frac{D_{2}-d_{2}}{2}+\frac{L}{2}-R, \frac{D_{2}-d_{2}}{2}\right] .
\end{aligned}
$$

3.3. The Solution of the Load Capacity Model. To get the numerical implement of stable load capacity, the value of $p(z)$ should be determined firstly. Based on (15), $p(z)$ is determined by $R, L, \mu, Y \mathrm{~s}$, and $b_{0}$, and all parameters except $b_{0}$ could be selected positively. The parameter $b_{0}$ is related to the maximum embedded depth of the steel ball gouging into the inner and outer tubes $\Delta L$; however, it is difficult to get an analytical relation for $b_{0}$. We investigate the relationship between $\Delta L$ and $b_{0}$ via numerical simulation in this section.

3.3.1. The Determination of $b_{0}$. We study the contact problem between the steel ball and the tube using finite element method. The simulation model is shown in Figure 5. In the model, a plain stress condition is adopted. According to the former assumptions, the steel ball is indeformable, and the material of prop has perfect plastic character. 
TABLE 1: Property parameters for the model.

\begin{tabular}{lc}
\hline Parameters & Value \\
\hline Radius of steel ball $(R / \mathrm{mm})$ & 2.5 \\
The gap distance between inner and outer tube $(L / \mathrm{mm})$ & 1 \\
Prescribed displacement in $Y$ direction $\left(U_{y} / \mathrm{mm}\right)$ & 2 \\
Length of inner tube $(l / \mathrm{mm})$ & 100 \\
Wall thickness of inner tube $(h / \mathrm{mm})$ & 10 \\
Young's modulus of inner tube $\left(E_{1} / \mathrm{GPa}\right)$ & 210 \\
Poisson's ratio of steel ball and inner tube $(\nu)$ & 0.3 \\
Friction coefficient between the steel ball and inner & 0.03 \\
tube $(\mu)$ & 690 \\
Yield strength of inner tube $\left(Y_{S} / \mathrm{MPa}\right)$ & \\
\hline
\end{tabular}

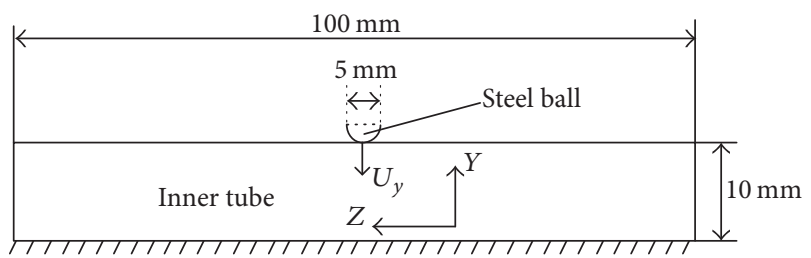

Figure 5: The contact model between the steel ball and the inner tube in axial direction.

In the model, the steel ball radius and the gap between the inner and outer tubes are $2.5 \mathrm{~mm}$ and $1 \mathrm{~mm}$, respectively. The wall thickness of the inner tube is $10 \mathrm{~mm}$. To eliminate the boundary effect, the length of the inner tube is $100 \mathrm{~mm}$. The inside of the inner tube is fixed, and the other boundaries are free. According to (3), the maximum embedded depth is $2 \mathrm{~mm}$. So, the displacement of steel ball in $Y$ direction is prescribed as $2 \mathrm{~mm}$.

The property parameters used in the simulation are listed in Table 1.

Figure 6 shows the simulation results for the plastic area evolution as the steel ball gouging inner tube. It is clear that the plastic zone depth increases as the steel ball is digging into the prop.

The relation between the maximum plastic zone depth of the inner tube and embedded depths of steel ball is presented in Figure 7. It shows that the maximum plastic zone depth of the inner tube increases with the embedded depth of steel ball. With the increase of the embedded depth of the steel ball, the increase rate of the maximum plastic zone depth decreases.

3.3.2. The Theoretical Calculation Results of the Stable Load Capacity. Combining (14) to (19) with boundary conditions from (21) to (23), the mechanical model was established to analyze the stable load capacity for the new prop with one ball. Using the parameter in Table 1, we solve the equations by the Simpson formula in MATLAB and get the stable load capacity with one ball. The result is $44.5 \mathrm{kN}$.

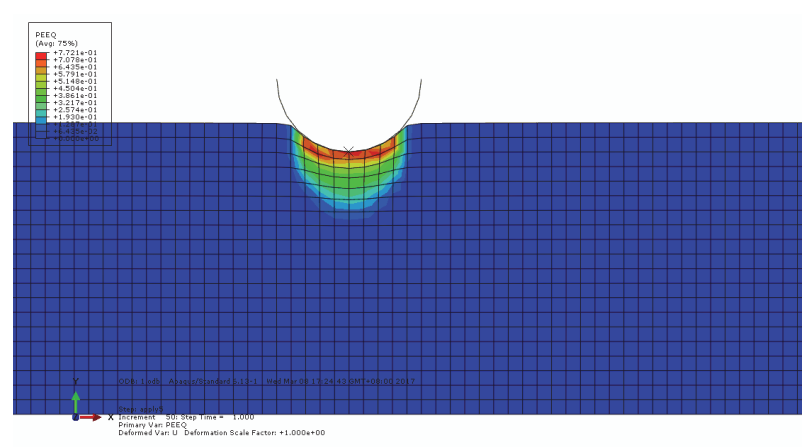

(a) The embedded depth is $1 \mathrm{~mm}$

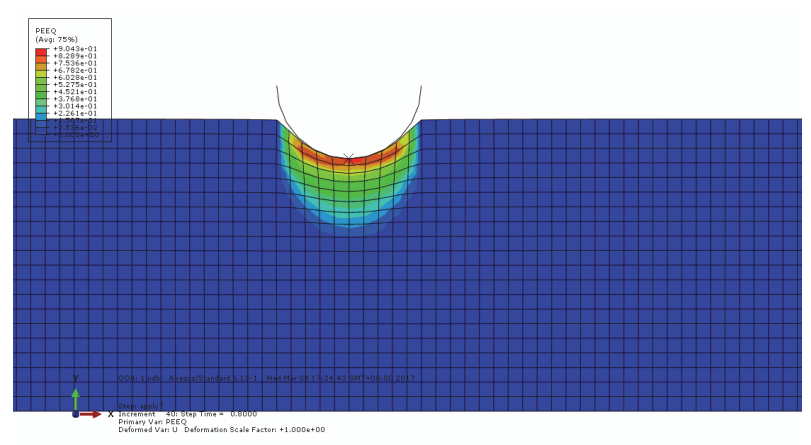

(b) The embedded depth is $1.5 \mathrm{~mm}$

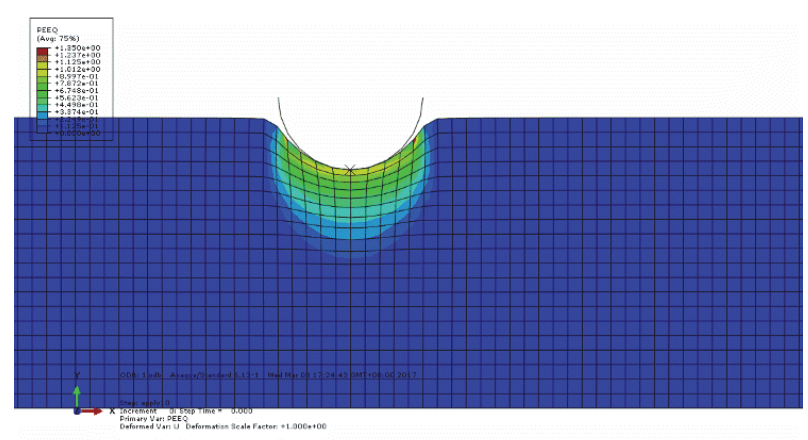

(c) The embedded depth is $2 \mathrm{~mm}$

FIGURE 6: The plastic zone depth of the inner tube in the $Y$ direction under different embedded depth of the steel ball.

\subsection{Discussion on the Factors Affecting the Load Capacity of the Prop}

3.4.1. The Steel Ball Number. If the steel balls are tightly placed around the gap between the inner and outer tubes, the plastic regions induced by the balls may overlap with each other and increase the plastic zone depth of inner tube in the $Y$ direction. In addition, if the balls contact with each other, the radius force on the inner tube is decreased, and so does the plastic zone depth in the $Y$ direction. Both of the two factors influence the stable load capacity. Therefore, there should be an optimal distance between each ball, which can overcome the ball contact and plastic area superposition problems. This has already been investigated by the numerical method. The 
TABLE 2: Property and geometry parameters of the model.

\begin{tabular}{lc}
\hline Parameters & Value \\
\hline Radius of steel ball $(R / \mathrm{mm})$ & 2.5 \\
The outer diameter of the inner tube $\left(D_{2} / \mathrm{mm}\right)$ & 90 \\
The inner diameter of the inner tube $\left(d_{2} / \mathrm{mm}\right)$ & 70 \\
Young's modulus of inner tube $\left(E_{1} / \mathrm{GPa}\right)$ & 210 \\
Poisson's ratio of steel ball and prop $(\nu)$ & 0.3 \\
Friction coefficient $(\mu)$ & 0.03 \\
Yield stress of inner tube $\left(Y_{S} / \mathrm{MPa}\right)$ & 690 \\
\hline
\end{tabular}

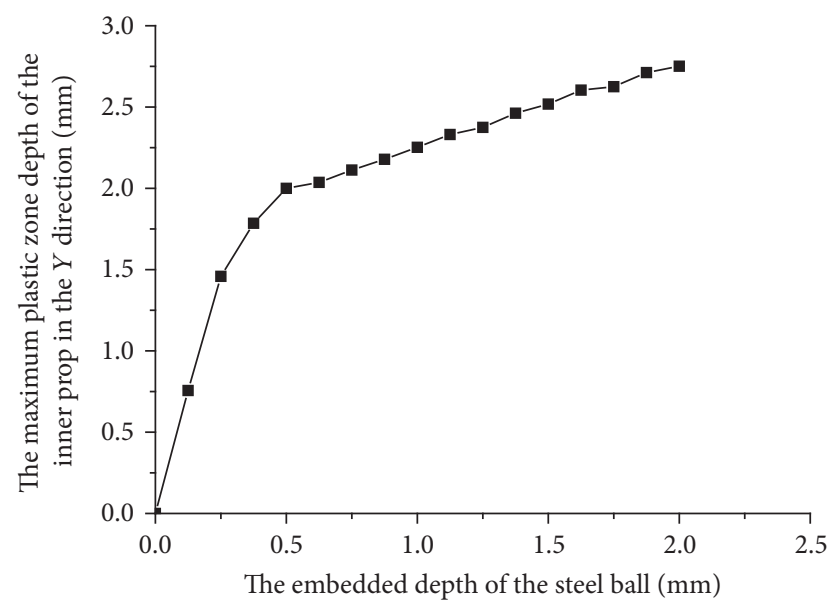

FIGURE 7: The relation between the maximum plastic zone depth of the inner tube in the $Y$ direction and the different embedded depths of steel ball.

model is shown in Figure 8. The geometry parameters of the model are illustrated in Table 2.

The range of plastic region caused by the interaction of one steel ball and the inner tube is shown in Figure 9.

Therefore, the maximum effective number $(n)$ of the steel balls can be calculated as

$$
n=\frac{360}{\theta}
$$

where $\theta$ is the radius angle corresponding to plastic field generated by the interaction between one steel ball and inner tube.

In this case, the value of $\theta$ is approximately $12^{\circ}$. According to (23), the maximum effective number of the steel balls is 30 .

In summary, the total stable load capacity of the prop with multiple steel balls is

$$
T=n * P,
$$

where $T$ is the total stable load capacity of the prop, $n$ is the effective number of steel balls, and $P$ is the stable load capacity with one steel ball got previously.

It is obviously seen that the total stable load capacity of the prop increases linearly with the increase of the effective number of the steel balls, and the prop reaches the maximum stable load capacity under the maximum effective number of the steel balls.

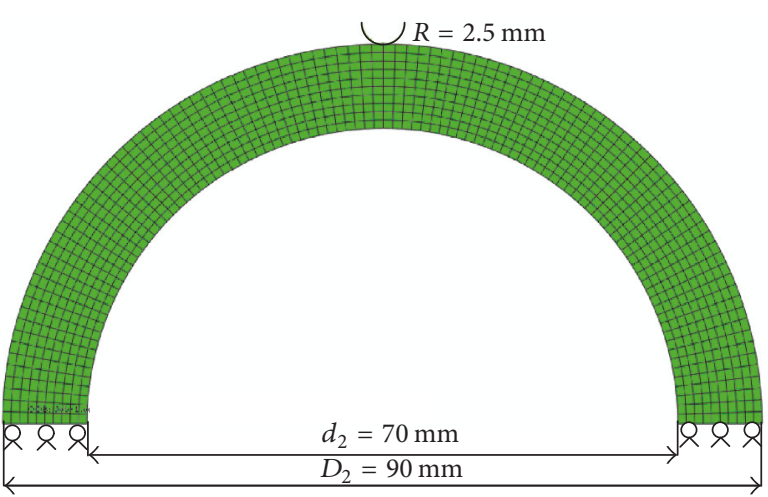

FIGURE 8: The contact model between ball and inner tube in radial direction.

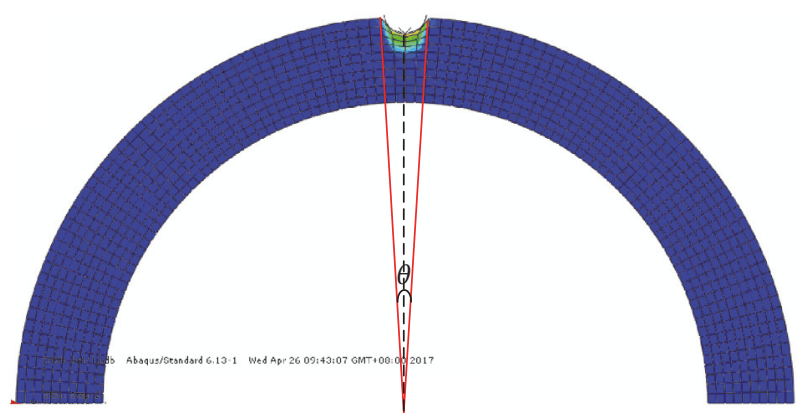

FIGURE 9: The range of plastic field generated by the interaction between one steel ball and inner tube.

3.4.2. The Radius of the Steel Ball and the Gap between the Inner and the Outer Tube. According to the previous results, when the gap between the inner tube and the outer tube is fixed, the load capacity of the prop with one steel ball increases and the effective number of steel balls decreases with the increase of the radius of the steel ball. Based on (24), the total stable load capacity of the prop is nonmonotonic variation. Figure 10 shows that relation between the radius of the steel ball and the stable load capacity of the prop. From the figure, it is seen that the stable load capacity of the prop increases initially and decreases afterwards with the increase of the radius of the steel ball. On the other hand, under the fixed radius of the steel ball, the stable load capacity will increase with the decrease of the gap between the inner tube and the outer tube. Therefore, after the material of the steel ball and the prop is fixed, the maximum load capacity can be obtained by changing the values of the radius of the steel ball and the gap between the inner tube and the outer tube.

\section{Stability Analysis of the New Yielding Steel Prop}

For a yielding prop, the critical buckling load must be at least $20 \%$ higher than the stable load capacity to prevent premature failure [29]; it could be calculated by

$$
P_{\mathrm{cr}}=1.2 T \text {, }
$$

where $P_{\mathrm{cr}}$ is the buckling load of the prop. 


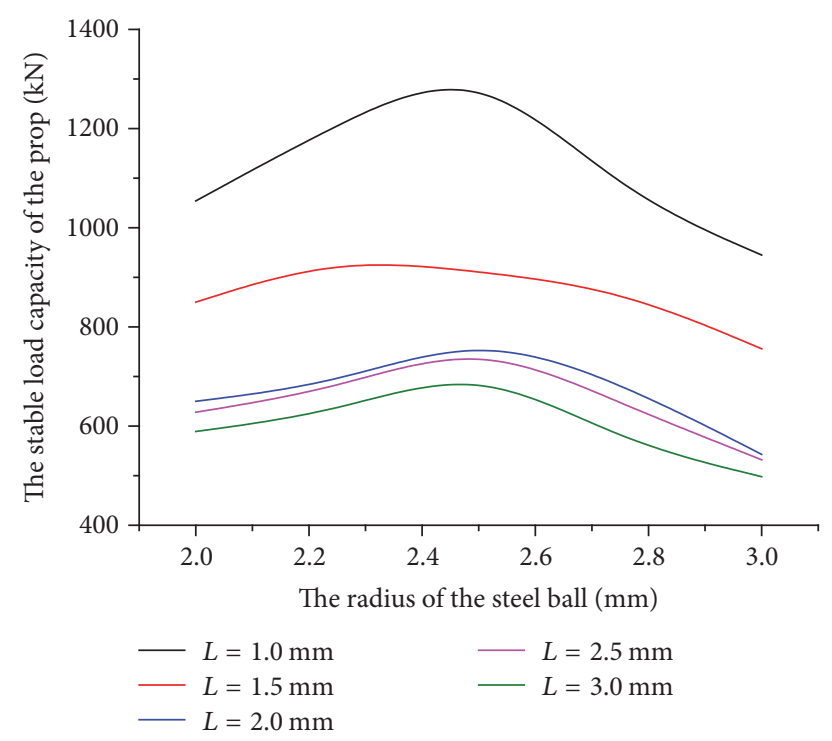

FIGURE 10: The relation between the radius of the steel ball and the stable load capacity of the prop.

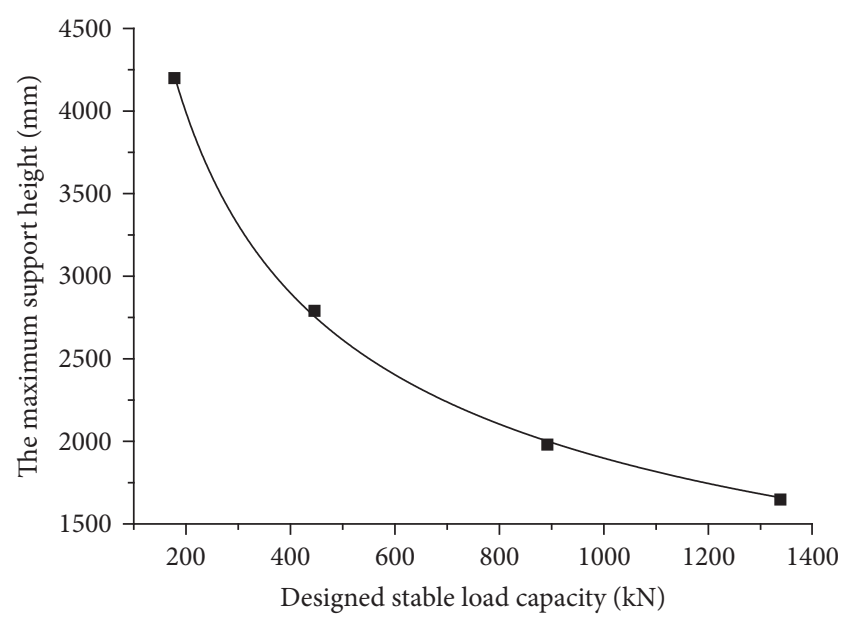

FIGURE 11: The relation between the maximum support height and the designed stable load capacity.

Based on Euler's formula [33], the maximum support height under stability condition is

$$
H=\frac{\pi}{\lambda} \sqrt{\frac{E I}{P_{\mathrm{cr}}}}
$$

where $P_{\text {cr }}$ is the critical buckling load of the yielding steel prop, $E$ is Young's Modulus of prop material, $H$ is the maximum support height of the prop, and $\lambda$ is the length coefficient; in this case, the value is one, and $I$ is crosssectional area moment of inertia of the inner tube, which is calculated as

$$
I=\frac{\pi\left(D_{2}^{4}-d_{2}^{4}\right)}{64} .
$$

Based on (25), (26), and (27), the maximum support height under the designed stable load capacity can be determined, as shown in Table 3 and Figure 11. It can be seen

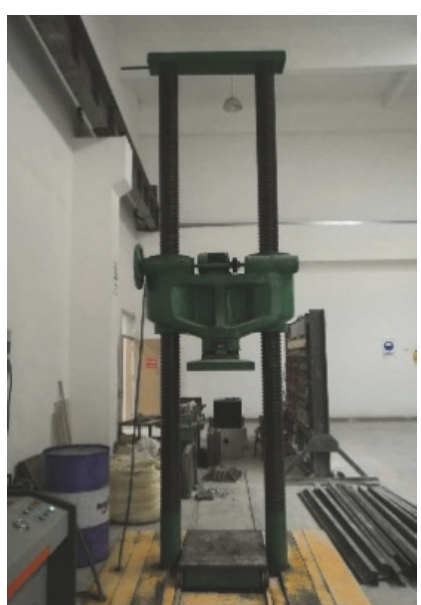

FIGURE 12: The NSY500 testing machine.

that the maximum support of the prop height is power function decrease with the increase of the designed stable load capacity.

\section{Experimental Study}

5.1. Test Method. In order to verify the proposed theoretical model, a series of tests were conducted in the laboratory. The testing system was NSY500 stress testing machine, as shown in Figure 12. The specific parameters for the testing machine are as follows:

(1) The maximum size of the specimen is $500 \mathrm{~mm} \times$ $500 \mathrm{~mm} \times 3000 \mathrm{~mm}$

(2) The maximum axial load is $5000 \mathrm{kN}$.

(3) The single maximum load displacement is $300 \mathrm{~mm}$.

(4) The total maximum load displacement is $4500 \mathrm{~mm}$.

The configuration of the prop during the test is indicated in Figure 13. The property and geometry parameters of the prop specimens are listed in Table 4.

5.2. Test Results. The load-displacement curves were obtained as shown in Figure 14. In the figure, the four loaddisplacement curves illustrate the movement process of new yielding steel prop. Before reaching the stable load capacity, the load is approximate linear growth with the displacement. Moreover, with more effective number of steel balls, the prop has the more rapid speed to reach its stable load capacity. Specifically speaking, when the number of the balls is 30 , the prop reaches its stable load capacity after deforming for approximately $25 \mathrm{~mm}$; on the other hand, when the number of the balls is 4 , the prop achieves the stable load capacity after deforming for about $175 \mathrm{~mm}$. The result also indicates that the inner tube had experienced a linear elastic and elastic-plastic behavior, and the movement process obtained by tests agreed well with the analysis shown in Figure 2.

Comparisons of the stable load capacity obtained from theoretical model and the tests are given in Table 5. It is seen 
TABLE 3: The maximum support height under the designed stable load capacity.

\begin{tabular}{lccc}
\hline $\begin{array}{l}\text { Designed stable load } \\
\text { capacity }(T / \mathrm{kN})\end{array}$ & $\begin{array}{c}\text { The outer diameter of } \\
\text { the inner tube }\left(D_{2} / \mathrm{mm}\right)\end{array}$ & $\begin{array}{c}\text { The inner diameter of } \\
\text { the inner tube }\left(d_{2} / \mathrm{mm}\right)\end{array}$ & $\begin{array}{c}\text { The maximum support } \\
\text { height }(H / \mathrm{mm})\end{array}$ \\
\hline 200 & 90 & 70 & 70 \\
450 & 90 & 70 & 2800 \\
900 & 90 & 70 & 2000 \\
1300 & 90 & 1650 \\
\hline
\end{tabular}

TABLE 4: Property and geometry parameters of specimens.

\begin{tabular}{lccccccc}
\hline Prop specimens & $R(\mathrm{~mm})$ & $L(\mathrm{~mm})$ & $\Delta L(\mathrm{~mm})$ & $D_{2}(\mathrm{~mm})$ & $d_{2}(\mathrm{~mm})$ & $Y s(\mathrm{Mpa})$ & $n$ \\
\hline 1 & 2.5 & 1 & 2 & 90 & 70 & 690 & 60 \\
2 & 2.5 & 1 & 2 & 90 & 90 & 690 \\
3 & 2.5 & 1 & 2 & 90 & 70 & 690 & 20 \\
4 & 2.5 & 1 & 2 & 90 & 70 & 690 \\
\hline
\end{tabular}

TABLE 5: Stable load capacity calculated by theoretical model and by tests for different specimens.

\begin{tabular}{lcccc}
\hline Prop specimens & Number of steel balls & $\begin{array}{c}\text { Stable load capacity calculated by } \\
\text { theoretical model }(\mathrm{kN})\end{array}$ & $\begin{array}{c}\text { Stable load capacity by tests } \\
(\mathrm{kN})\end{array}$ & Relative rate $(\%)$ \\
\hline 1 & 4 & 178 & 185 & 3.8 \\
2 & 10 & 446 & 468 & 4.7 \\
3 & 20 & 892 & 920 & 3.0 \\
4 & 30 & 1338 & 1400 & 4.4 \\
\hline
\end{tabular}

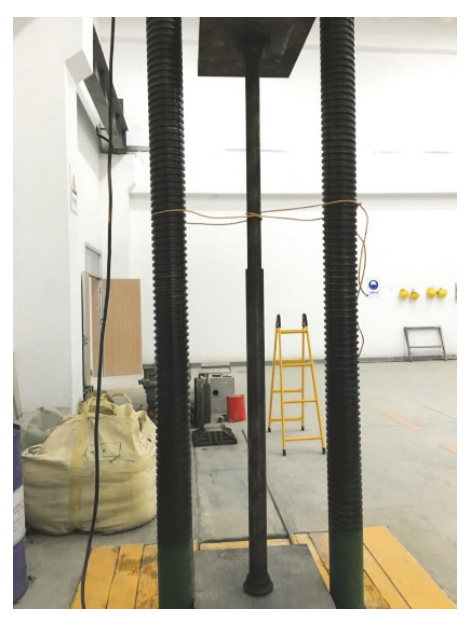

(a)

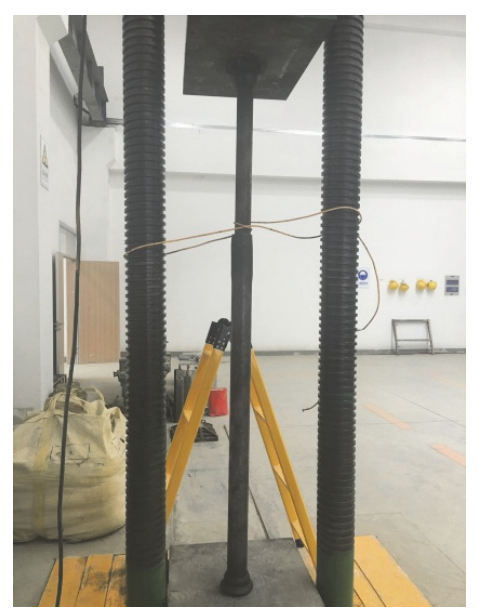

(b)

FIGURE 13: The testing of stable load capacity of prop. (a) The initial state and (b) the stable load capacity state.

that the relative error is less than $5 \%$, which indicates that the theoretical model of the stable load capacity for the prop is effective.

\section{Conclusions}

Based on the results of theoretical analysis and numerical simulation, the mechanical and mathematical models of the stable load capacity for the new yielding steel prop were proposed, and a series of tests were carried out to verify the calculation results. The following conclusions can be drawn:

(1) The working mechanism of the new yielding steel prop is that the steel balls gouge both inner and outer tubes, by generating plastic deformation to support the load. Comparing with hydraulic prop, high and stable load capacity of the yielding steel prop can be achieved. 


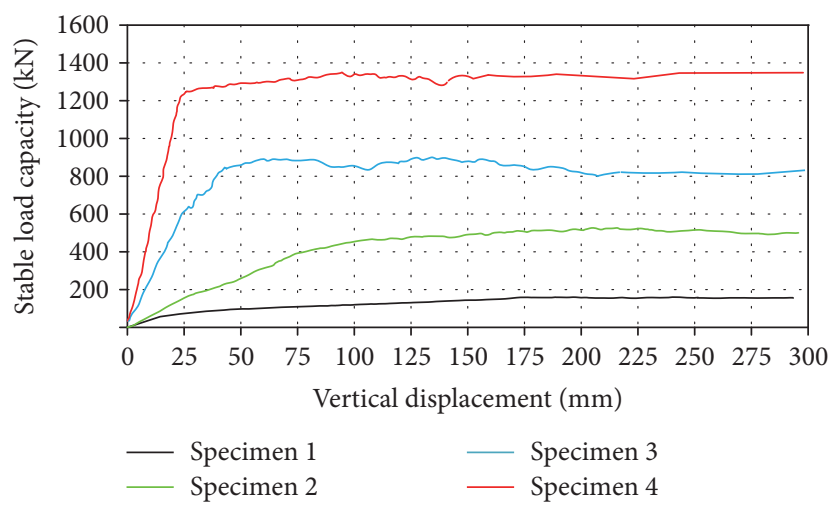

FIGURE 14: Comparison of the load-displacement curve of four specimens.

(2) It shows that the maximum plastic zone depth of the inner tube increases with the embedded depth of steel ball. With the increase of the embedded depth of steel ball, the increase rate of the maximum plastic zone depth will decrease.

(3) The stable load capacity of the prop increases linearly with the increase of the effective number of the steel balls, and with more effective number of steel balls, the prop will have more rapid speed to reach its stable load capacity. It can be seen that the maximum support height of the prop is power function decrease with the increase of the designed stable load capacity.

(4) The stable load capacity of the prop increases initially and decreases afterwards with the increase of the radius of the steel ball. For the fixed radius of the steel ball, the stable load capacity will increase with the decrease of the gap between the inner tube and the outer tube.

(5) Comparing the stable load capacity of the prop specimens by testing machine and theoretical model, it is seen that the relative error of tested and calculated results is less than 5\%. It indicates that the theoretical model of the stable load capacity of prop is proved.

\section{Conflicts of Interest}

The authors declare that there are no conflicts of interest regarding the publication of this paper.

\section{Acknowledgments}

The authors acknowledge financial support by the Fundamental Research Funds for the Central Universities (2015QNA60), the National Natural Science Foundation of China (51674247), and the Priority Academic Program Development of Jiangsu Higher Education Institutions (PAPD).

\section{References}

[1] H. W. Zhou, H. P. Xie, and J. P. Zuo, "Developments in researches on mechanical behaviors of rocks under the condition of high ground pressure in the depths," Advances in Mechanics, vol. 35, no. 1, pp. 191-199, 2005.

[2] Y. N. He, L. J. Han, P. Shao, and B. S. Jiang, "Some problems of rock mechanics for roadways stability in depth," International Journal of Mining Science and Technology, vol. 35, no. 3, pp. 288295, 2006.

[3] Q. Meng, L. Han, Y. Chen et al., "Influence of dynamic pressure on deep underground soft rock roadway support and its application," International Journal of Mining Science and Technology, 2015.

[4] H. Lan, D. K. Chen, and D. B. Mao, "Current status of deep mining and disaster prevention in China," Coal Science and Technology, vol. 44, no. 1, pp. 39-46, 2016.

[5] M.-C. He, H.-P. Xie, S.-P. Peng, and Y.-D. Jiang, "Study on rock mechanics in deep mining engineering," Chinese Journal of Rock Mechanics and Engineering, vol. 24, no. 16, pp. 2803-2813, 2005 (Chinese).

[6] Q. S. Liu, H. Zhang, and T. Lin, "Study on stability of deep rock roadways in coal mines and their support measures," Chinese Journal of Rock Mechanics and Engineering, vol. 23, no. 21, pp. 3732-3737, 2004.

[7] M. C. He, "Latest progress of soft rock mechanics and engineering in China," Journal of Rock Mechanics and Geotechnical Engineering, vol. 6, no. 3, pp. 165-179, 2014.

[8] Y. Chen, Q. Meng, G. Xu, H. Wu, and G. Zhang, "Bolt-grouting combined support technology in deep soft rock roadway," International Journal of Mining Science and Technology, 2015.

[9] H. Zhou, C.-K. Qu, D.-W. Hu et al., "In situ monitoring of tunnel deformation evolutions from auxiliary tunnel in deep mine," Engineering Geology, vol. 221, pp. 10-15, 2017.

[10] Z. Yu, P. H. S. W. Kulatilake, and F. Jiang, "Effect of tunnel shape and support system on stability of a tunnel in a deep coal mine in China," Geotechnical and Geological Engineering, vol. 30, no. 2, pp. 383-394, 2012.

[11] W. J. Wang, C. Yuan, W. J. Yu et al., "Stability control method of surrounding rock in deep roadway with large deformation," Journal of China Coal Society, vol. 41, no. 12, pp. 2921-2931, 2016.

[12] M. S. Gao, Q. S. Yang, Y. C. Zhao, Z. C. Cheng, and X. C. Quan, "Support technology and device development of yield cables for the high stress and large deformation roadway," Journal of Mining and Safety Engineering, vol. 33, no. 1, pp. 7-11, 2016.

[13] H. P. Kang, J. H. Wang, and J. Lin, "Case studies of rock bolting in coal mine roadways," Chinese Journal of Rock Mechanics and Engineering, vol. 29, no. 4, pp. 649-664, 2010.

[14] Q. Li, W. J. Liu, R. S. Yang, J. W. Hao, and S. U. Peng, “Technology of secondary bolt-shotcreting coupling support for deep rock roadway," Journal of Mining and Safety Engineering, vol. 25, no. 3, pp. 256-262, 2008.

[15] J.-C. Chang and G.-X. Xie, "Mechanical characteristics and stability control of rock roadway surrounding rock in deep mine," Journal of the China Coal Society, vol. 34, no. 7, pp. 881886, 2009.

[16] H. T. Liu, F. Wang, G. H. Wang, X. D. Zhao, D. Tang, and M. $\mathrm{J}$. Yu, "Research on lengthening bolt roof support system performance in largely deformed roadway," Journal of China Coal Society, vol. 39, no. 4, pp. 600-607, 2014.

[17] M. C. He, C. Li, W. L. Gong, L. R. Sousa, and S. L. Li, “Dynamic tests for a Constant-Resistance-Large-Deformation bolt using a modified SHTB system," Tunnelling and Underground Space Technology, vol. 64, pp. 103-116, 2017. 
[18] X.-M. Sun, M.-C. He, and X.-J. Yang, "Research on nonlinear mechanics design method of bolt-net-anchor coupling support for deep soft rock tunnel," Rock and Soil Mechanics, vol. 27, no. 7, pp. 1061-1065, 2006.

[19] Y. Chen and C. C. Li, "Performance of fully encapsulated rebar bolts and D-Bolts under combined pull-and-shear loading," Tunnelling and Underground Space Technology, vol. 45, pp. 99106, 2015.

[20] H. Kang, Y. Wu, F. Gao, J. Lin, and P. Jiang, "Fracture characteristics in rock bolts in underground coal mine roadways," International Journal of Rock Mechanics and Mining Sciences, vol. 62, pp. 105-112, 2013.

[21] W. Korzeniowski, K. Skrzypkowski, and Ł. Herezy, "Laboratory method for evaluating the characteristics of expansion Rock bolts subjected to axial tension," Archives of Mining Sciences, vol. 60, no. 1, pp. 209-224, 2015.

[22] Q. Pan, S. Liu, X. Li, and C. Xu, "Characteristic evaluation on bolt stress by ultrasonic nondestructive methods," Advances in Materials Science and Engineering, vol. 2015, no. 2, Article ID 134090, 6 pages, 2015.

[23] L.-G. Wang, M.-Y. Li, and X.-Z. Wang, "Study of mechanisms and technology for bolting and grouting in special soft rock roadways under high stress," Chinese Journal of Rock Mechanics and Engineering, vol. 24, no. 16, pp. 2889-2893, 2005.

[24] L. Malmgren and E. Nordlund, "Interaction of shotcrete with rock and rock bolts-A numerical study," International Journal of Rock Mechanics and Mining Sciences, vol. 45, no. 4, pp. 538553, 2008.

[25] P. K. Kaiser and M. Cai, "Design of rock support system under rockburst condition," Journal of Rock Mechanics and Geotechnical Engineering, vol. 4, no. 3, pp. 215-227, 2012.

[26] V. Sorin and V. Niculina, "Hydraulic props of powered roof supports as safety face elements," in Proceedings of the Manufacturing Science and Education, pp. 449-452, June 2011.

[27] R. Juárez-Ferreras, C. González-Nicieza, A. Menéndez-Díaz, A. E. Álvarez-Vigil, and M. I. Álvarez-Fernández, "Forensic analysis of hydraulic props in longwall workings," Engineering Failure Analysis, vol. 16, no. 7, pp. 2357-2370, 2009.

[28] X. Zhao, F. Li, Y. Liu, and Y. Fan, "Fatigue behavior of a boxtype welded structure of hydraulic support used in coal mine," Materials, vol. 8, no. 10, pp. 6609-6622, 2015.

[29] S. Spearing, "Designing free-standing steel supports for coal mine roof support," in Proceedings of the 27th International Conference on Ground Control in Mining, pp. 366-373, July 2008.

[30] K. L. Johnson, Contact Mechanics, Cambridge University Press, Cambridge, UK, 1985.

[31] N. A. Fleck, K. L. Johnson, M. E. Mear, and L. C. Zhang, "Cold rolling of foil," Proceedings of the Institution of Mechanical Engineers, vol. 206, no. 2, pp. 119-131, 1992.

[32] H. R. Le and M. P. F. Sutcliffe, "Robust model for rolling of thin strip and foil," International Journal of Mechanical Sciences, vol. 43, no. 6, pp. 1405-1419, 2001.

[33] H. W. Liu, Mechanics of Materials, Higher Education Press, Beijing, China, 1991. 


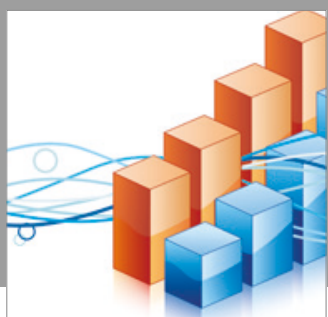

Advances in

Operations Research

vatersals

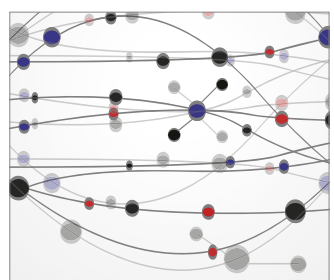

\section{The Scientific} World Journal
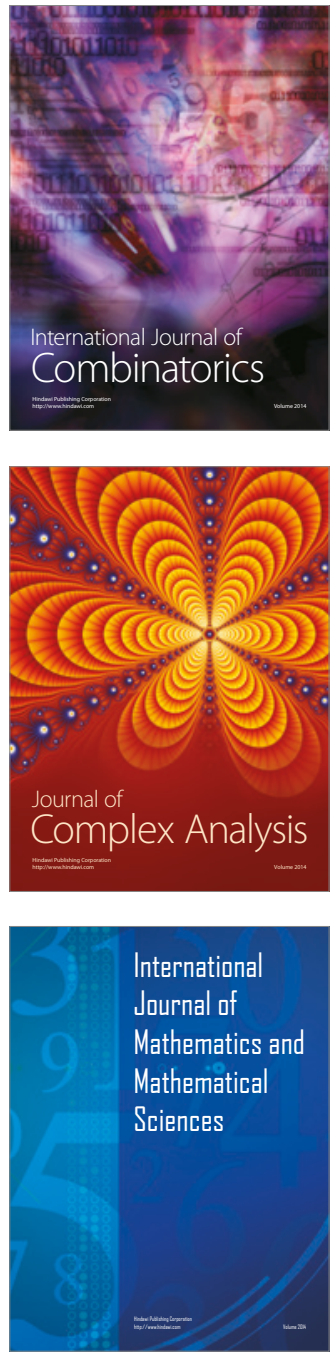
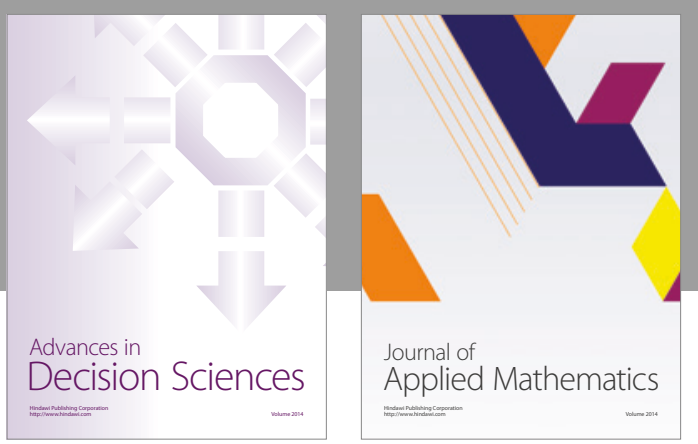

Algebra

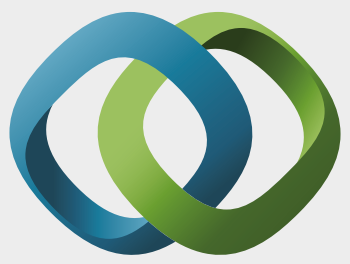

\section{Hindawi}

Submit your manuscripts at

https://www.hindawi.com
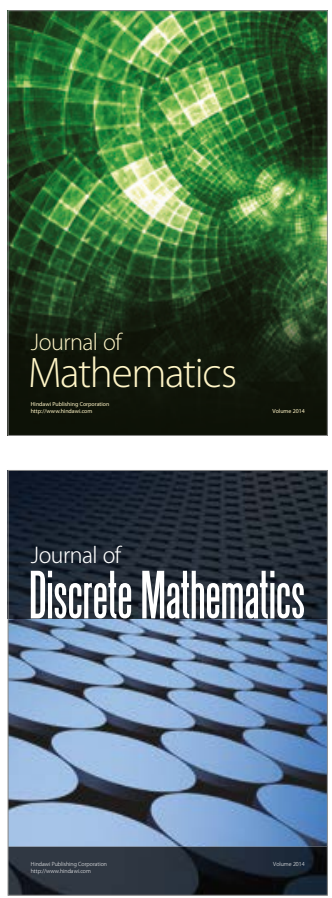

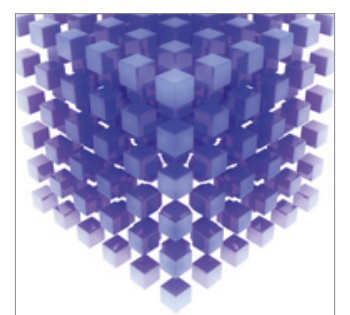

Mathematical Problems in Engineering
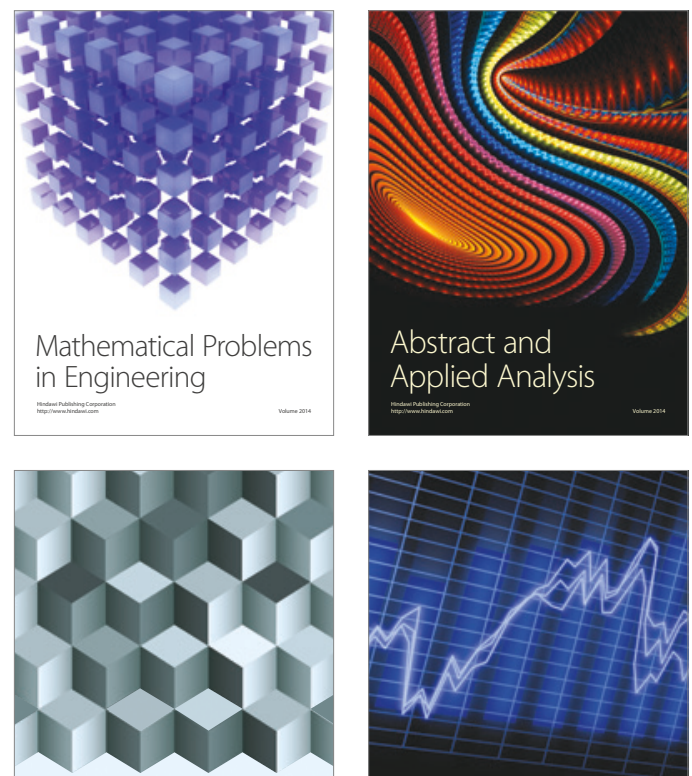

Journal of

Function Spaces

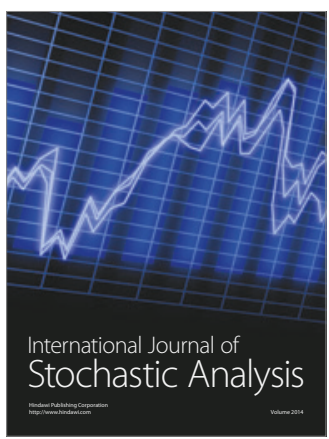

Probability and Statistics
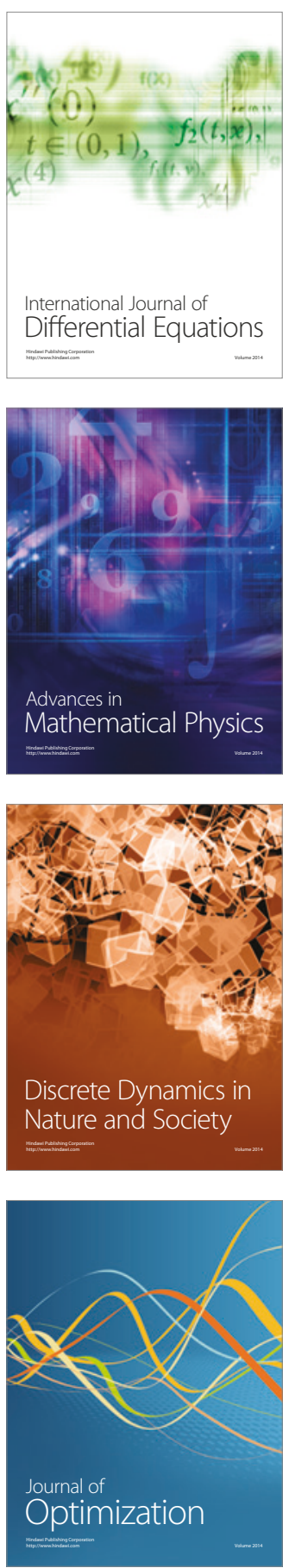